\title{
Polarization Analysis of Planar Solid Oxide Fuel Cells
}

\author{
Toshihiko YOSHIDA* , Hideto KOIDE, Motoo ANDOH, Isao MUKAIZAWA, \\ Yoshiyuki SOMEYA and Atsushi TSUNODA
}

\author{
Received December 18, 1995 ; Accepted March 7, 1996
}

\begin{abstract}
Planar single solid oxide fuel cells with a $50 \times 50 \times 0.2 \mathrm{~mm}$ electrolyte were investigated in order to identify constituents which contributed voltage loss during discharge. A study of 250 cells showed that voltage loss during discharge could be attributed chiefly to IR resistance which consists of material resistance of the cell, contact resistance and unknown resistance. Under a discharge condition of $80 \%$ fuel utilization and current density of $0.31 \mathrm{~A} / \mathrm{cm}^{2}$, it was estimated that activation polarization accounted for approximately $21 \%$ of voltage loss, diffusion polarization accounted for approximately $7 \%$, and that IR resistance accounted for approximately $72 \%$ of the loss. Additional studies showed that a cell used with hydrogen fuel has an electrical efficiency of $45 \%$ when the power density is $0.18 \mathrm{~W} / \mathrm{cm}^{2}$ and a cell used with methane fuel has a $50 \%$ efficiency at $0.16 \mathrm{~W} / \mathrm{cm}^{2}$. Thus, it was concluded that cell performance could be improved with the reduction of IR resistance.
\end{abstract}

\section{INTRODUCTION}

Much research has been devoted to the development of a solid oxide fuel cell (SOFC). Recently, attention has been focused on the planar configurations due to ceramics technology advances such as the development of thin zirconia sheets. In this configuration, SOFCs are made up of sintered electrolytes with electrodes and interconnectors, which are stacked one after another. Planar stack tests at 1.3 $\mathrm{kW}$ confirmed that the stacking of cells is easy to assemble and has a high volumetric density and moreover, the output of $5.1 \mathrm{~kW}$ was reported ${ }^{1,2)}$.

Concerning the tubular configuration SOFC, Westinghouse Electric Corporation has reported the results of SOFC performance with $85 \%$ fuel utilization $^{3)}$. Concerning the planar configurations, Tonen developed a $50 \times 50 \mathrm{~mm}$ planar single cell and a 3stack $200 \times 200$ cell, and obtained an electrical efficiency of $40 \%$ with a power density of $0.2 \mathrm{~W} / \mathrm{cm}^{2}$ ${ }^{4,5)}$. In this paper, results of an electrochemical SOFC investigation indicated that SOFC has an electrical efficiency of over $50 \%$. Furthermore, this paper will present data related to specific voltage loss and resistance on the planar configuration.

Corporate Research \& Development Laboratory, TONEN Corporation, (1-3-1 Nishi-tsurugaoka, Iruma-gun, Saitama 356, JAPAN)

Key Words; fuel cell, zirconia, ceramics, planar

\section{EXPERIMENTAL}

$50 \times 50 \mathrm{~mm}$ planar single cells were investigated. Refer to Fig. 1 for the assembly concept of a planar cell. The anode, cathode and sealant were painted on both sides of sintered yttria-doped zirconia electrolyte with an active area of $16 \mathrm{~cm}^{2} . \mathrm{Ni} / \mathrm{ZrO}_{2}$, $\mathrm{La}(\mathrm{Sr}) \mathrm{MnO}_{3}$ and glass were used as the anode, cathode and sealant, respectively. The thickness of the electrolyte was approximately $0.2 \mathrm{~mm}$. Sintered $\mathrm{La}(\mathrm{Sr}) \mathrm{Cr}(\mathrm{Co}) \mathrm{O}_{3}$, metal and metal alloys were used as interconnecting and separating materials. They were ground and formed into gas paths, and fuel and oxidant was cross-fed into the manifold, as shown in Fig. 1. The cells were heated to $1000^{\circ} \mathrm{C}$ and the temperature was kept constant.

In order to measure maximum power output and open-circuit voltage, hydrogen was fed in at 200 $\mathrm{cc} / \mathrm{min}$ and oxygen at $100 \mathrm{cc} / \mathrm{min}$.

To measure the discharge properties, a 4 probe method was used. Two platinum probes were connected to each separator. Current interruption was performed in order to measure the resistance. When the current was switched from $3 \mathrm{~A}$ to off a voltage shift was observed within $5 \mu \mathrm{sec}$. IR resistance (R) was calculated from voltage shifts between the separators.

In the case of 5 single cells, a platinum wire (c') was embedded into the cathode. The resistance between the cathode side separator and 'c' was assigned as the cathode-separator contact resistance (Rc). 


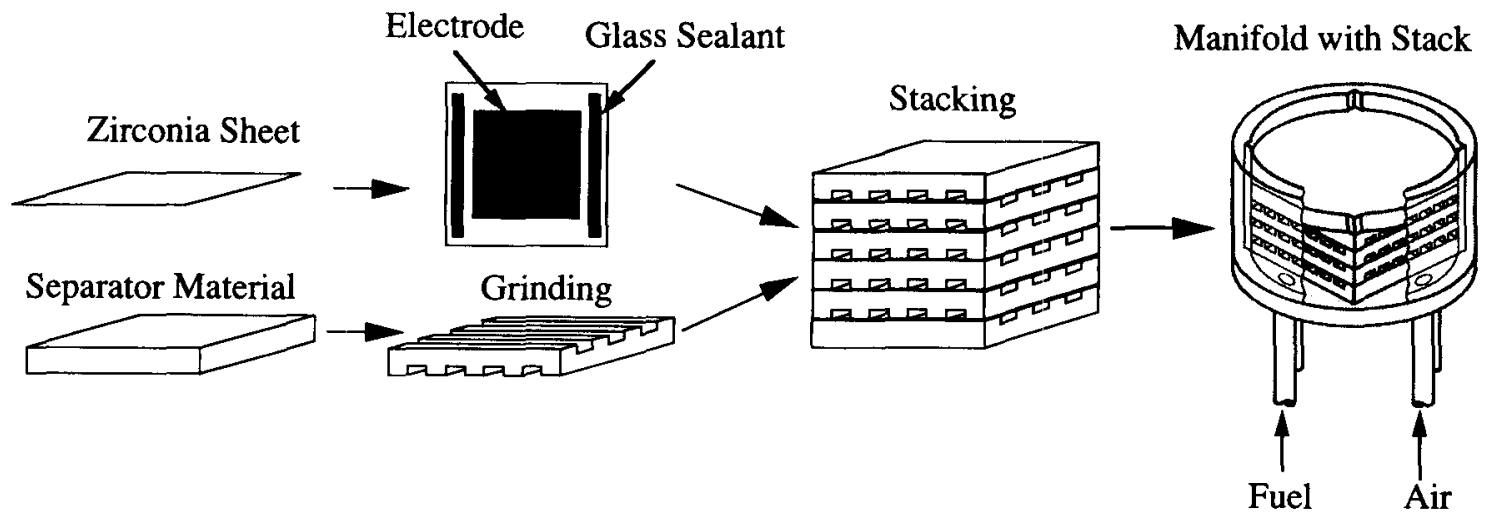

Fig. 1 Assembly concept of a planar SOFC.

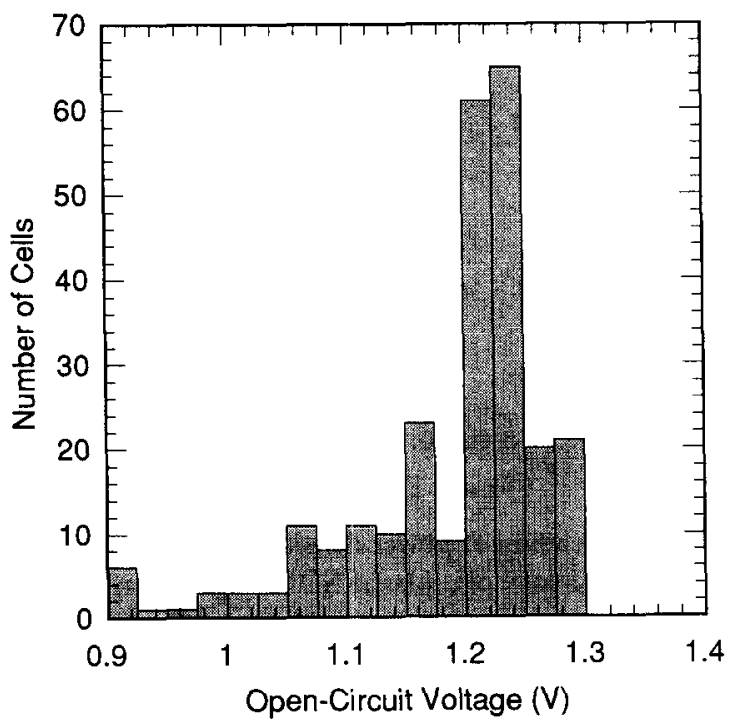

Fig. 2 Plot of number of cells versus open-circuit voltage of cell.

$200 \mathrm{cc} / \mathrm{min}$ of hydrogen as anode gas, 100 $\mathrm{cc} / \mathrm{min}$ of oxygen as cathode gas

In the case of 2 cells, electrode polarization was measured. Single cell polarization consists of the sum of activation polarization of both electrodes (SAP), the diffusion polarization of the anode (DPA) and a diffusion polarization of the cathode (DPC). Polarization was evaluated under a constant discharge current of $5 \mathrm{~A}$. In the case of low fuel utilization $u_{1}$ and oxygen feed, the sum of activation polarization (SAP) on both electrodes was defined as follows:

$$
\mathrm{SAP}=\mathrm{V}_{0}-(5 \times \mathrm{R})-\mathrm{Vm}
$$

where $V_{0}$ was the theoretical voltage at $u_{1}$ and $V m$

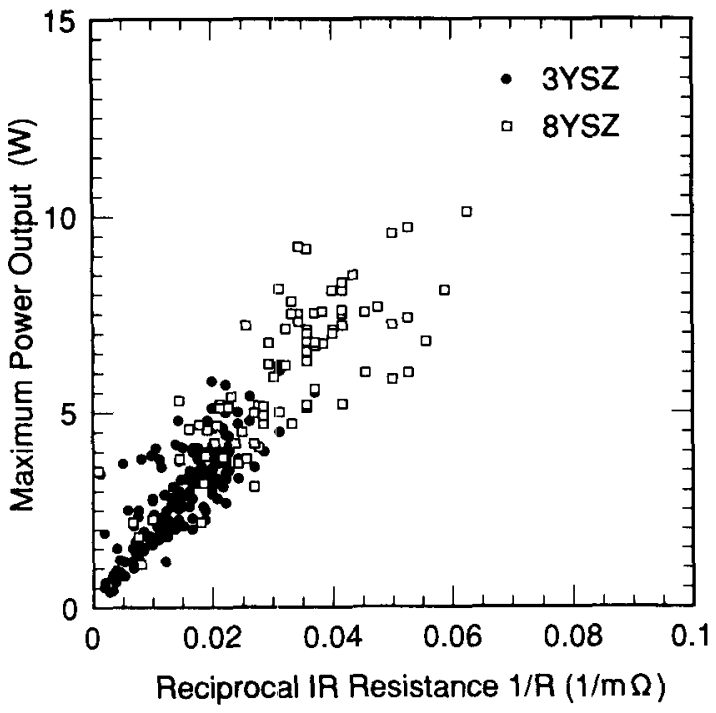

Fig. 3 Relationship between the maximum power output on reciprocal value of IR resistance. 250 planar cells with $16 \mathrm{~cm}^{2}$ active area. $200 \mathrm{cc} / \mathrm{min}$ of hydrogen as anode gas, 100 $\mathrm{cc} / \mathrm{min}$ of oxygen as cathode gas

was the measuring cell voltage. This paper deals with the polarization of assembly structure at an practical operation. The diffusion polarization in this structure may be influenced by the gas flow rates at the paths, the gas diffusion at sandwich spaces between electrodes and libs of the separator, the current density and fuel utilization. SOFC will be practically operated at a high fuel utilization such as $80 \%$. Hence, DPA was calculated from a voltage drop ( $\delta \mathrm{Va}$ ) accompanied by fuel utilization shift from $u_{1}$ to $u_{2}$ and it was defined as follows: 
Table 1 Resistances of 5 cells with $16 \mathrm{~cm}^{2}$ active area.

\begin{tabular}{lrrrrr}
\hline & \multicolumn{5}{c}{ Resistance } \\
\cline { 2 - 6 } \multicolumn{1}{c}{ Cell Number } & 1 & 2 & 3 & 4 \\
IR resistance (R) & 37 & 18 & 25 & 37 & 27 \\
Cathode-separator contact resistance (Rc) & 18 & 10 & 19 & 15 & 11 \\
R-Rc-Rm $^{\text {a) }}$ & 11 & 0 & -2 & 14 & 8 \\
\hline
\end{tabular}

a) Calculated value where total material resistance $(\mathrm{Rm})$ is estimated to be $8 \mathrm{~m} \Omega$

Table 2 Results on polarization at $\mathrm{u}_{\mathrm{f}}=\mathbf{8 0 \%}$ and current density at $0.3 \mathrm{~A} / \mathrm{cm}^{2}$.

\begin{tabular}{|c|c|c|}
\hline \multirow[b]{2}{*}{ Cell Number } & \multicolumn{2}{|c|}{$\begin{array}{c}\text { Voltage drop } \\
(\mathrm{mV})\end{array}$} \\
\hline & 6 & 7 \\
\hline $\begin{array}{l}\text { Sum of activation polarization on } \\
\text { both electrodes (SAP) }\end{array}$ & 48 & 36 \\
\hline $\begin{array}{l}\text { Diffusion polarization of anode } \\
\text { (DPA) }\end{array}$ & 3 & 2 \\
\hline $\begin{array}{l}\text { Diffusion polarization of cathode } \\
\text { (DPC) }\end{array}$ & 10 & 12 \\
\hline
\end{tabular}

$\mathrm{DPA}=\delta \mathrm{Va}-(\mathrm{RT} / 2 \mathrm{~F}) \ln \left[\left(1-\mathrm{u}_{1}\right) / \mathrm{u}_{1} \times \mathrm{u}_{2} /\left(1-\mathrm{u}_{2}\right)\right]$

DPC was calculated from the decrease in voltage with the shift from oxygen to air.

$\mathrm{An} \mathrm{La}(\mathrm{Sr}) \mathrm{Cr}(\mathrm{Co}) \mathrm{O}_{3}$ interconnector was used and air was fed so as to measure cell efficiency. The electrical power efficiency $\eta$ was defined as:

$$
\eta=\left(\mathrm{Vm} \times \mathrm{u}_{\mathrm{f}}\right) / \mathrm{LHV}
$$

$\mathrm{u}_{\mathrm{f}}$ and LHV denote fuel utilization and the lower heating value in the $\mathrm{eV}$ unit, respectively. Methane and hydrogen were used as fuel. Methane diluted by steam was fed to a cell and was directly reformed in the anode. The experimental detail was presented in a previous paper ${ }^{5}$.

\section{RESULTS}

In between 1990 and 1993, 2:50 hand-fabricated cells were manufactured from a variety of alloy separator( $\mathrm{Cr}$ contents of alloy), Co contents of $\mathrm{La}(\mathrm{Sr}) \mathrm{Cr}(\mathrm{Co}) \mathrm{O}_{3}$ separator, anode and cathode components and 3 or $8 \mathrm{~mol} \%$ yttria contents in electrolyte, furthermore, each was pressed by a variety of weights. All cells were tested and as a result, each cell performed differently. It was found that cells with $3 \mathrm{~mol} \%$ yttria-doped zirconia (3YSZ) generated a lower power output than cells with $8 \mathrm{~mol} \%$ yttria doped-zirconia(8YSZ).

Data regarding the number of cells tested and the open-circuit voltage are shown in Fig. 2. 85\% of the

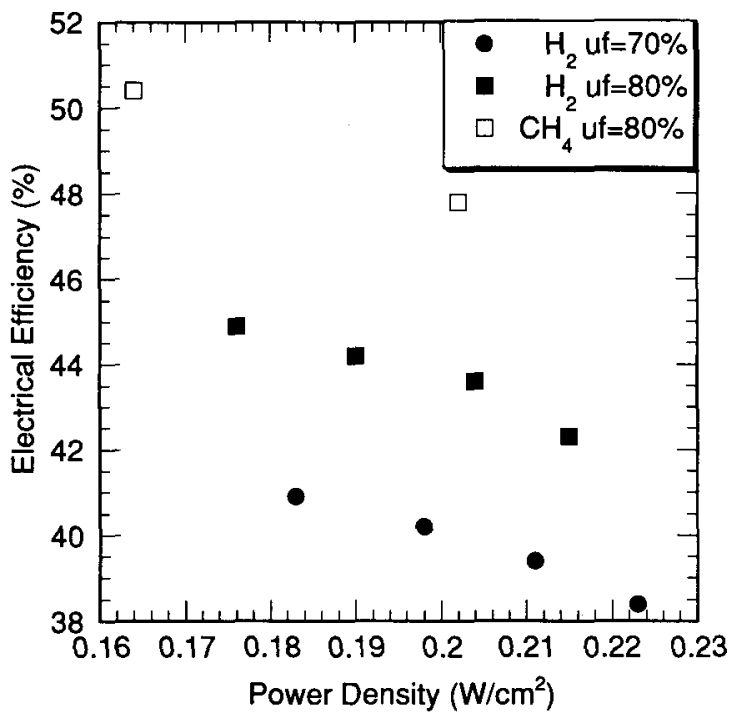

Fig. 4 Relation of power density and electrical efficiency of a planar SOFC with $16 \mathrm{~m}^{2}$ active area: hydrogen utilization $(\bigcirc) 70 \%$, (G) $80 \%$, directly fed methane utilization ( $\square$ ) $80 \%$ with steam/carbon $=2.5$.

cells had a voltage above 1.1 . Of those, $65 \%$ had a voltage greater than 1.2 .

Figure 3 refers to the relationship between maximum power values and the reciprocal values of IR resistance ( $1 / R)$. It can been seen that there is a correlation between maximum power values and the reciprocal value of IR resistance. At the highest maximum power value of $10.5 \mathrm{~W}$, the power density was calculated to be $0.65 \mathrm{~W} / \mathrm{cm}^{2}$.

Cathode contact resistance and IR resistance in 5 cells are shown in Table 1. IR resistance ranged widely from 18 to $37 \mathrm{~m} \Omega$. The contact resistance ranged from 10 to $19 \mathrm{~m} \Omega$, which corresponded to between 40 and $76 \%$ of the IR resistance.

Table 2 shows the polarization effects from 2 cells with $5 \mathrm{~A}$ operating current when the hydrogen fuel utilization was shifted from $17.5 \%\left(\mathrm{u}_{1}\right)$ to $80 \%$ 
$\left(u_{2}\right)$. DPA was significantly lower than both DPC and SAP.

Figure 4 shows the relation between the power density and electrical efficiency of cell with an IR resistance of $23 \mathrm{~m} \Omega$. An electrical efficiency value of $45 \%$ was obtained at a power density of 0.176 $\mathrm{W} / \mathrm{cm}^{2}$ with hydrogen fuel. An efficiency greater than $50 \%$ at $0.164 \mathrm{~W} / \mathrm{cm}^{2}$ with methane fuel $(2.5$ steam/carbon) was achieved.

\section{DISCUSSION}

\subsection{Assumption on the estimation of polarization}

The experimental involved 4 assumptions at least.

(i) For the simplicity, a fuel pressure in a cell was set to $P_{0} u_{f}$ where $P_{0}$ denotes an inlet fuel pressure of manifold and $\mathrm{P}_{0} \mathrm{u}_{\mathrm{f}}$ was applied to the calculation of $\mathrm{V}_{0}$. Such an approximation is known as the ideal mixing reactor ${ }^{6)}$

(ii) The potential of probe $c^{\prime}$ is equal to that of the cathode.

(iii) The difference of diffusion polarization between uf $=0 \%$ and $15 \%$ influences insignificantly SAP value into equation (1).

(iv) Gas leakage was not viewed as a factor.

Deviation from these assumptions would cause errors in SAP.

\subsection{Voltage decrease factors}

When the open-circuit voltage was above $1.2 \mathrm{~V}$, there was virtually no cross-leakage because fed hydrogen and oxygen into manifold contains a few content of impurities. The Nernst equation obtained the voltage of $1.1 \mathrm{~V}$ for approximately $4 \%$ of crossleakage. The planar SOFC proved to be virtually leakproof.

The IR resistance value was obtained from $\mathrm{AC}$ impedance which has proven valuable as a method for reaction kinetics analysis and was applied to the cells smaller than $1 \mathrm{~cm}^{2}$ of electrodes area ${ }^{7,89}$. However, the AC impedance signal decreases as the cell area increases and furthermore, reactance noise increases. Therefore, current interruption, SAP, DPC and DPA were applied in this research.

If the relationship between cell voltage $\mathrm{Vm}$ and cell current $I$ was determined by $V m=V_{0}-I R$, then power output $\mathrm{VI}$ is $\mathrm{VI}=\left(\mathrm{V}_{0} \mathrm{~V}-\mathrm{V}^{2}\right) / \mathrm{R}$. The power output was approximately proportional to the reciprocal of IR resistance 1/R as shown in Fig.3, where both electrodes in the cells would have low polarization because $u_{f}$ was operating below $5 \%$ and oxygen was fed. Thus, IR resistance mainly constitutes cell voltage loss.

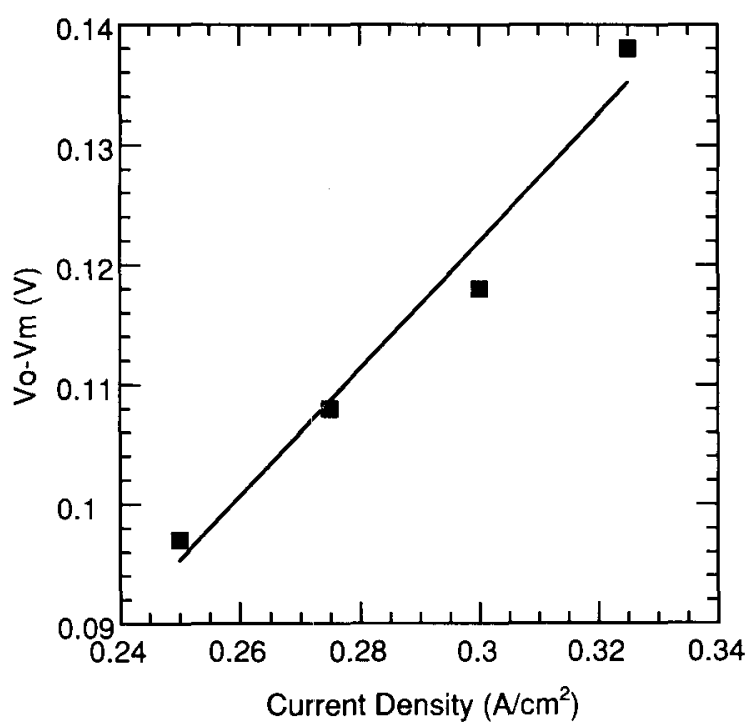

Fig. 5 Relation of current density and the difference between theoretical voltage and measuring voltage $\left(\mathrm{V}_{\mathrm{o}}-\mathrm{Vm}\right)$ : hydrogen utilization $80 \%$.

IR resistance normally consists of the material resistance of electrolyte and the interconnector, the contact resistance between electrode and interconnector and the collecting current resistance in electrodes. The material resistance of $8 \mathrm{YSZ}$ electrolyte is about $8 \mathrm{~m} \Omega$ at $1000^{\circ} \mathrm{C}$ and resistance of the interconnector is less than $1 \mathrm{~m} \Omega$ because its electrical conductivity is greater than $10 \Omega^{-1} \mathrm{~cm}^{-1}$, hence the total material resistance $\mathrm{Rm}$ is approximately $8 \mathrm{~m} \Omega$ As for the 5 cells shown in Table 1, the values of the differences $R-R c-R m$ were calculated and ranged from -2 to $14 \mathrm{~m} \Omega$. A minimum value of no less than 0 should have occurred, however, a negative value of $-2 \mathrm{~m} \Omega$ was recorded. This may have been due to a measuring error. The range was abnormally wide even if a negative value was disregarded It was concluded that R-Rc-Rm may depend upon the unknown resistance that arises from the mechanical connection of the platinum probe and the $\mathrm{La}(\mathrm{Sr}) \mathrm{Cr}(\mathrm{Co}) \mathrm{O}_{3}$ separator or the contact between electrode particles in porous electrodes.

A definition of DPC includes the activation polarization with shift from oxygen to air, therefore, the diffusion polarization values may be lower than the DPC shown in Table 2

The average values shown in Tables 1 and 2 comprise of components that contribute to the voltage decrease of cells under the polarized condition of $\mathrm{u}_{\mathrm{f}}=80 \%$ and current density of $0.3 \mathrm{~A} / \mathrm{cm}^{2}$. SAP constituted of a decrease of $21 \%$; DPA+DPC, $7 \%$; Rm, 
$20 \%$; Rc, 37\%; and unknown resistance, $15 \%$.

\subsection{Specific Resistance}

Specific resistance of a cell, which is described by a unit of $\mathrm{m} \Omega \cdot \mathrm{cm}^{2}$, may be defined as $\left(\mathrm{V}_{0}-\mathrm{Vm}\right) /$ current density. This value illustrates the cell performance, although it may be nominal because it varies depending on the current density.

The data $u_{\mathrm{f}}=80 \%$ from Fig. 4 was replotted to show the relation between current density and $V_{0^{-}}$ Vm. Refer to Fig. 5. The data are plotted to form a straight line and the slope of the line gives a specific resistance of $530 \mathrm{~m} \Omega \cdot \mathrm{cm}^{2}$. On the other hand, average specific resistance of $640 \mathrm{~m} \Omega \cdot \mathrm{cm}^{2}$ is estimated by a summarization of the average values of $\mathrm{R}, \mathrm{SAP}$ and DPA+DPC which were $464(=29 \mathrm{~m} \Omega$ $\left.\times 16 \mathrm{~cm}^{2}\right), 134\left(=42 \mathrm{mV} / 5 \mathrm{~A} \times 16 \mathrm{~cm}^{2}\right), 45$ $\left(=13.5 \mathrm{mV} / 5 \mathrm{~A} \times 16 \mathrm{~cm}^{2}\right) \mathrm{m} \Omega \cdot \mathrm{cm}^{2}$, respectively as shown in Tables 1 and 2 .

The difference in specific resistance in Fig. 5 and the average value of $640 \mathrm{~m} \Omega \cdot \mathrm{cm}^{2}$ might be caused by differences in IR resistance.

It can be suggested that an ideal cell will have specific resistance consisting of the minimum resistance from Fig. 3 and the polarizations found in Tables 1 and 2 . Such a cell may have an electrical efficiency of $50 \%$ achieved at $0.19 \mathrm{~W} / \mathrm{cm}^{2}$ for methane fuel.

\section{CONCLUSION}

The performance of a planar SOFC was investigated using $50 \times 50 \mathrm{~mm}$ planar cells in order to identify the factors that contribute to voltage loss during operation. IR resistance, which consists of the material resistance, contact resistance and unknown resistance, was the main contributor to the decrease in voltage. The IR resistance ranged widely among cells. It was obtained that activation polarization contributed to $21 \%$ of the voltage decrease, that dif- fusion polarization caused $7 \%$ and that the average specific resistance was $640 \mathrm{~m} \Omega \cdot \mathrm{cm}^{2}$ under the operating conditions of $80 \%$ fuel utilization and 0.3 $\mathrm{A} / \mathrm{cm}^{2}$. This study indicates that reduction of IR resistance will improve planar cell performance.

This work was partially supported by the Petroleum Energy Center which was subsidized by MITI.

\section{References}

1) S.Sakurada and T. Yoshida, Proceedings of The 2nd Internal Symposium on Soild Oxide Fuel Cells, Greece, p 45 (1991).

2) T. Yoshida, A. Tsunoda, Y. Someya, T. Hoshina, H. Seto, H. Koide, S. Wakayama, M. Andoh, I. Mukaizawa, F. Ishizaki, J. Nishimura, N. Ohmori, N. Itoh and K. Nakata, Proceedings of The 9th Gijutsukaihatsukenkyuuseikahapyou, Petroleum Energy Center, p 402 (1995).

3) S.C. Singhal, Proceedings of The 3 rd Internal Symposium on Soild Oxide Fuel Cells, p665 (1993).

4) Y.Someya, H. Koide, M. Andoh and T. Yoshida, Proceedings of The 4th Internal Symposium on Soild Oxide Fuel Cells, Yokohama, p 86 (1995).

5) H. Koide, Y. Someya and T. Yoshida, Fuel Cell Seminar Abstracts, San Diego, p 33 (1994).

6) $O$. Levenspiel, Chemical Reaction Engineering, Wiley International, New York, p97 (1972).

7) N. Nakagawa, C. Kuroda and M. Ishida, Solid State Ionics, 40/41, 411 (1990).

8) O. Yamamoto, Y.Takeda, R. Kanno, Y. Tomita, J.Chemical Soc. of Japan, No.8,1324(1988).

9) J. Mizusaki, H. Tagawa, K. Tsuneyoshi, K. Mori and A. Sawata, J. Chemical Soc. of Japan, No.9, 1623 (1988). 